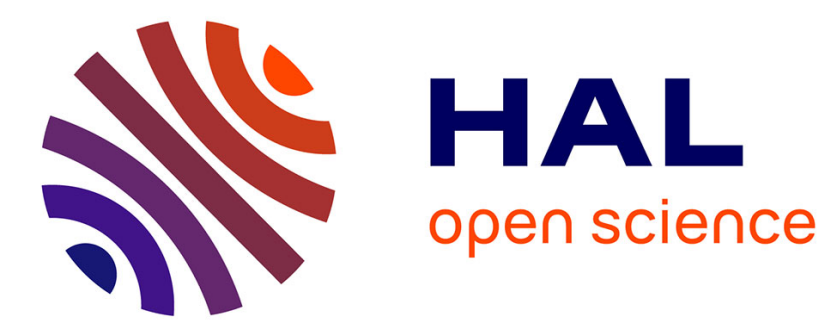

\title{
Wideband analysis of the railway catenary line radiation and new applications of its unintentional emitted signals
}

\author{
Marc Heddebaut, Virginie Deniau, Jean Rioult
}

\section{To cite this version:}

Marc Heddebaut, Virginie Deniau, Jean Rioult. Wideband analysis of the railway catenary line radiation and new applications of its unintentional emitted signals. Measurement Science and Technology, 2018, 29 (6), 14p. 10.1088/1361-6501/aab07f . hal-01987795

\section{HAL Id: hal-01987795 \\ https://hal.science/hal-01987795}

Submitted on 21 Jan 2019

HAL is a multi-disciplinary open access archive for the deposit and dissemination of scientific research documents, whether they are published or not. The documents may come from teaching and research institutions in France or abroad, or from public or private research centers.
L'archive ouverte pluridisciplinaire HAL, est destinée au dépôt et à la diffusion de documents scientifiques de niveau recherche, publiés ou non, émanant des établissements d'enseignement et de recherche français ou étrangers, des laboratoires publics ou privés. 


\title{
Wideband analysis of the railway catenary line radiation and new applications of its unintentional emitted signals
}

\author{
Marc Heddebaut, Virginie Deniau, Jean Rioult \\ Department components and systems, the French institute of science and technology for transport, \\ development and networks, 20 rue Elisée Reclus F-59666 Villeneuve d'Ascq Cedex \\ E-mail : marc.heddebaut@gmail.com
}

\begin{abstract}
Generally, railway dissipated energy and its consequences in terms of noise, ballast attrition, electromagnetic interference... is considered as a nuisance generated by the railway transport mode. Therefore, most studies are carried out in order to reduce it. This paper takes the opposite view and considers the particular case of the irreducible electromagnetic interference generated along an electrified line to introduce new applications beneficial to railway operations. At a selected representative location, wideband, ranging from $10 \mathrm{kHz}$ to $1 \mathrm{GHz}$, electromagnetic field measurements are performed successively during or not during high speed train passages. We deduce two potential applications of these unintentional signals. At low frequency, the first proposal considers energy harvesting using the received electromagnetic interference as the source. This received energy can be converted and used to DC feed low consumption sensors to be installed along the railway infrastructure. These sensors participate in the monitoring of the infrastructure health and in making it more resilient to internal and external aggressions. At higher frequencies, for the second proposal, radiation of the catenary line and train pantograph is specifically examined at a carefully selected sub-band. The results are also studied following a time-frequency analysis to introduce a new nondestructive inspection method of the sliding contact existing between the catenary line and the train pantograph. Ultimately, this technique could offer a new means of monitoring both the health of the catenary line and of the pantograph.
\end{abstract}

Keywords. Electromagnetic interference, energy harvesting, time-frequency analysis, nondestructive inspection method, catenary line, railway engineering

\section{Introduction}

ECURITY and quality of life in industrialized countries depend on continuous and coordinated performance of a $N$ set of infrastructures (energy systems, information and communication technology systems, transportation...) which can, therefore, be defined as critical infrastructures [1,2]. Making these critical infrastructures more resilient to internal or external constraints is a major issue. As an example, the monitoring of overhead transmission lines has received a significant attention [3].

In its Strategic Rail Research Agenda 2020, the European Rail Research Advisory Council indicates that a European-wide intelligent infrastructure able to provide compatible technology between Member States and across transport modes is needed to support customer information systems. Furthermore, the Advisory Council mentions that "the railway maintenance is carried out in difficult conditions and often at night. Research is needed to reduce risk. Possible areas include the use of remote condition monitoring to create an intelligent infrastructure that can monitor and inspect itself." [4]. Indeed, monitoring and inspecting a very long railway infrastructure requires the development of specific techniques compatible with these stringent operating conditions [5]. One particular issue concerns the powering of this sensing equipment installed along the railway network. Although these sensors can be 
developed to operate with low energy consumption, they still require some power supply to acquire and transmit the requested data. Indeed, it would be quite unrealistic to get a main energy plug to feed this equipment everywhere it could be necessary along railway networks. Therefore, using specific rectifying antennas or rectennas [6,7] to harvest electric energy emanating from the railway infrastructure can be an interesting solution to consider. Since high electrical energy is involved in train traction, up to several MW per train can be consumed during traction phases, we make the preliminary assumption that electric energy harvesting could also be exploited in the close vicinity of the railway line [8,9]. From another perspective, let us now consider the following Fig. 1. This figure shows an example of a railway infrastructure with a high speed train running.

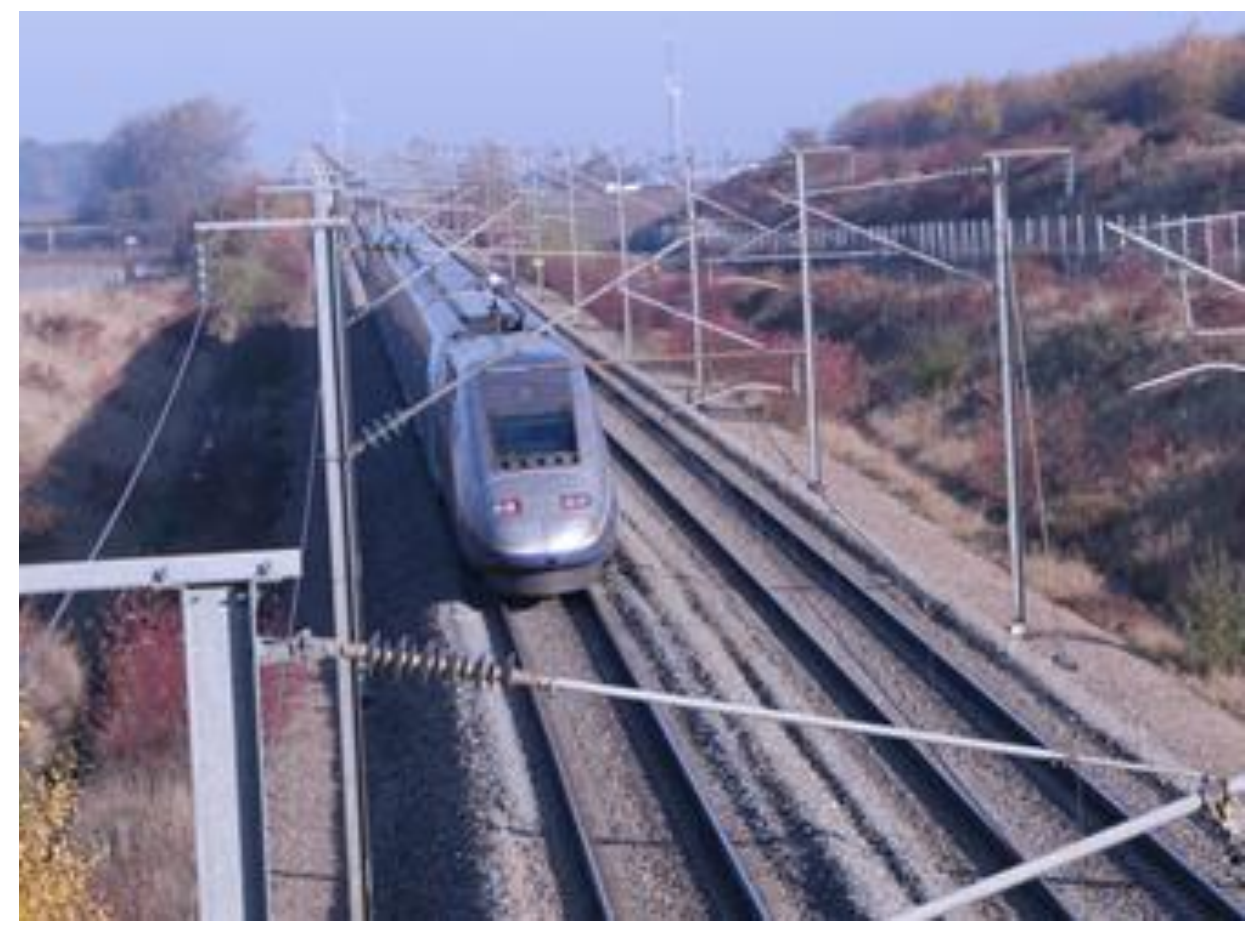

Fig. 1. Catenary line, pantograph and rail return current to feed the train electrical traction chain.

In particular, we observe the catenary line, connected to the train pantograph through a sliding contact, arcing while transferring electrical power from the catenary line to the train traction chain. Since a huge quantity of electrical energy is transferred through this sliding contact, arcing phenomena occur very frequently. In the electromagnetic spectrum also, a radiation is emitted, the characteristics of which are directly linked to the physical phenomenon involved in the generation of the electric arc [10,11]. Consequently, our second assumption is that, adequately exploiting these particular emitted signals can provide significant results to monitor both the health of the catenary and of the pantograph, at their sliding contact junction.

In this paper, trying to validate these two preceding assumptions, magnetic, noted $\mathrm{H}$, and then electric field, noted E, measurements are performed from $10 \mathrm{kHz}$ to $1 \mathrm{GHz}$ and recorded along a high speed railway line. The results are analyzed and the two new proposed applications are investigated. Firstly, considering the very large electrical power in use, energy harvesting from the received electromagnetic interference is considered as the source. Secondly, at higher frequencies, specific electromagnetic signatures directly linked to the train pantograph geometry working as an antenna fed by electrical arcs are analyzed. To more extensively exploit the available experimental conditions, measurements are performed during or not during train passages.

The rest of this paper is organized as follows. Section 2 describes the selected railway location and the measurement conditions we used between $10 \mathrm{kHz}$ and $1 \mathrm{GHz}$. Section 3 presents, measuring the magnetic field at low frequency, the results obtained while trains are circulating along the track, in line of sight, or not; this section also proposes some results and perspectives in terms of harvesting energy from this particular electromagnetic interference source. Section 4 provides the results obtained measuring the electric field at high frequency, and then concentrates on a particular high frequency sub-band of major interest; time-frequency signatures of different arcing conditions are presented and analyzed; perspectives linked to the development of a new monitoring and diagnostic system are proposed. Finally, section 5 synthesizes the major results and draws a conclusion. 


\section{Experimental measuring conditions}

\subsection{Antennas and laboratory van}

A measurement campaign was organized to evaluate the electromagnetic signals appearing along a railway infrastructure over a wide frequency range. The test site is located along the high speed train line between Lille and Paris in Northern France, approximately $80 \mathrm{~km}$ south of Lille. We selected a road bridge crossing a high speed line and installed our measurement equipment in a laboratory van parked over the bridge overhanging the railway line. In the laboratory van, the measuring instrumentation is autonomous in electrical energy and can be used for several consecutive hours, monitoring the electromagnetic activity either at this fixed location or, for other purposes, while the laboratory van is moving. Fig. 2 shows this particular location overhanging the railway infrastructure.

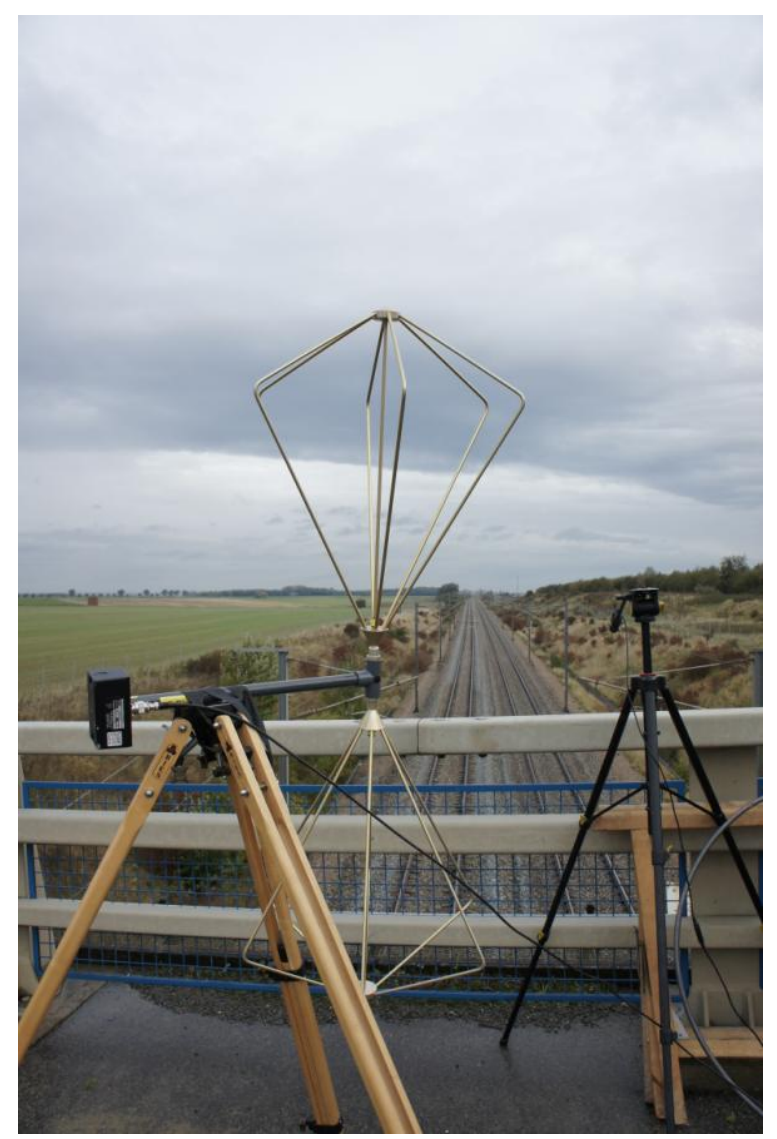

Fig. 2. Measuring antenna location over the railway track.

At low frequency, magnetic field measurements are generally preferred in electromagnetic compatibility measurements as electric field sensors have very limited effectiveness due to their reduced size in relation to the wavelength of the measured signals. At higher frequency, usually above $20 \mathrm{MHz}$, effective electric antennas like half wave dipoles or wider bandwidth antennas are used. In the Fig. 2, a biconical antenna is shown, a monopole antenna is additionally used for electric field measurements between $20 \mathrm{MHz}$ and $1 \mathrm{GHz}$. An active magnetic loop operating between $10 \mathrm{kHz}$ and $20 \mathrm{MHz}$ is also exploited at lower frequencies to measure the magnetic $\mathrm{H}$ field. Its diameter is $25 \mathrm{~cm}$.

To the right of the biconical antenna appearing in Fig. 2, there is also a video camera shooting the railway scene below the bridge. The output of this camera is used to monitor trains circulating or not along the line.

The following table 1 represents the different sensors we used for the studied frequencies. Considering the loop created by the catenary line and the rail return current, the selected location for measuring the radiated magnetic field does not provide a maximum potential coupling. Indeed, our measuring loop is situated over the railway line, not parallel and in front of the railway-catenary line loop. For safety reasons, it was not possible to operate at the railway level, close to the track. However, the selected location is almost ideal for electric field measurements of the catenary line to the pantograph sliding junction. 
Table 1. Used sensors according to the frequency.

Measurement

Sensor
Active magnetic loop antenna EMCO 6507
$20 \mathrm{MHz}$ to $\quad$ E field

$300 \mathrm{MHz}$

E field

Biconical antenna

AH Systems

SAS-540

$300 \mathrm{MHz}$ to $1 \mathrm{GHz}$
Monopole antenna over a circular reference plane laboratory built

Fig. 3 shows the rear of the laboratory van on which two display units were installed to be simultaneously surveyed by an operator outside the van. The left screen displays the output of the selected measurement instrument. In the case of this Fig. 3, a spectrum analyzer is used. On the right part, the monitor displays the track as captured by the video camera. These two displays are also simultaneously recorded on a camcorder for off-line analysis. So, using this setup, it was possible to estimate the emitted signals as trains are approaching the bridge, or we can also verify that no train is approaching while signals are recorded.

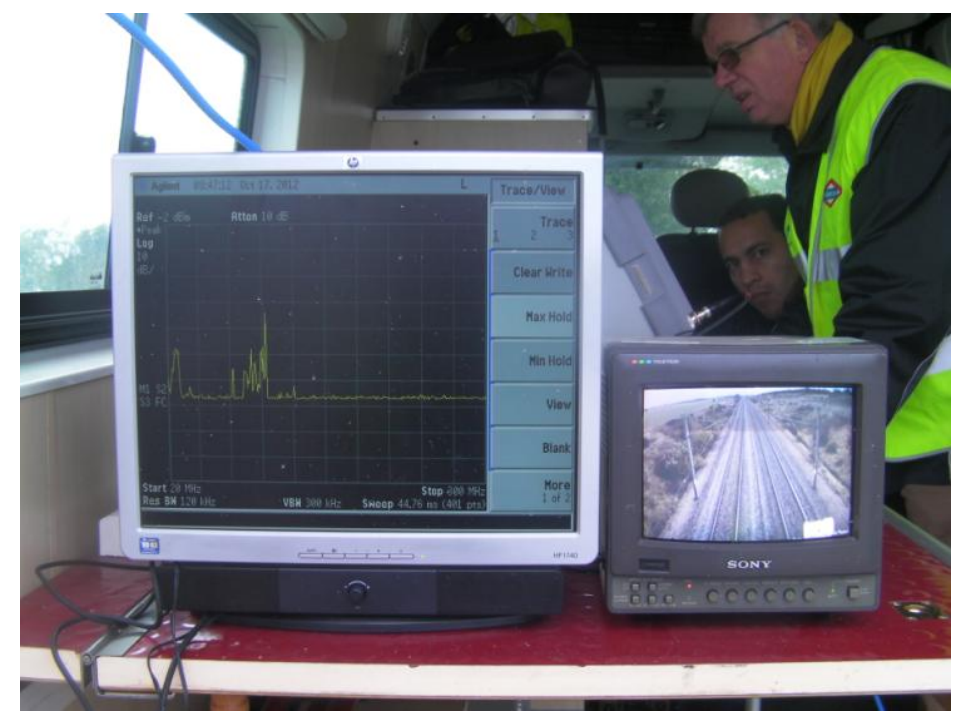

Fig. 3. Spectrum analyzer and video displays as seen by an operator looking at the rear of the laboratory van.

\subsection{Measuring equipment}

One Keysight PSA/ESA electromagnetic compatibility spectrum analyzer E7402A covering the $9 \mathrm{kHz}$ to $3 \mathrm{GHz}$ frequency band is used for spectrum analysis between $10 \mathrm{kHz}$ and $1 \mathrm{GHz}$. This bandwidth is limited by the covered range of the antennas used, but also, as we will verify in the following sections, by the bandwidth of the signals to be measured. For all the measurements concerning this particular piece of equipment, a resolution bandwidth of $120 \mathrm{kHz}$ is used, a $300 \mathrm{kHz}$ video bandwidth is applied, and 401 measuring points are selected. Sweep time is $80 \mathrm{~ms}$. Moreover, a real time signal analyzer, Agilent MXA operating between $10 \mathrm{~Hz}$ and $8.4 \mathrm{GHz}$ is also exploited for the time-frequency analysis presented in section 4. Both pieces of equipment are installed in the laboratory van, behind the display units seen in Fig. 3. The signals are recorded per period of $30 \mathrm{~s}$ corresponding to a train passage. Train visibility is estimated to $2 \mathrm{~km}$ on either side of the bridge. In this area, trains are usually circulating at a maximum speed of $300 \mathrm{~km} / \mathrm{h}$. Consequently trains circulate $2.5 \mathrm{~km}$ during any $30 \mathrm{~s}$ analyzed period. In addition, to obtain the results presented in the energy harvesting section 3, a peak hold detection method is used running for each $30 \mathrm{~s}$ of analysis. Therefore, in the hold mode, this corresponds to accumulate 375 consecutive sweep results on the spectrum analyzer. 


\section{Energy harvesting}

\subsection{Railway infrastructure potential sources of radiofrequency energy}

Fig. 4 shows a representation of an equivalent transmission line corresponding to a simple railway configuration. Railway electrical substations, separated from each other by up to several tens of kilometers, inject electrical energy into the catenary line. Through a sliding contact, this energy is delivered to distant trains circulating along this section of the track. After feeding the train traction system, the return currents flow into the rails and the electrical circuit closes at the remote electric substation. This way, we determine very long loops traveled by large currents that are several-kilometer long, several meters high. In the case of high speed trains operating at $25 \mathrm{kV} \mathrm{AC}$, at full speed, a train absorbs currents that can be more than $100 \mathrm{~A}$, for an overall train power consumption of several MW. Movement of the trains and variations of the train traction absorbed energy, or of the energy reinjected, during braking phases, modify the electromagnetic radiation characteristics of this large loop. This is also the case for fast current variations and transients due to degradations of the sliding contact which are linked to catenary line anomalies or to the pantograph electrical and mechanical alterations. Imperfect wheel to rail contacts can also contribute to the electromagnetic interference generated by such a large loop.

Fig. 4. Equivalent transmission line corresponding to a simple catenary line-rails configuration.

Since we are in the presence of a huge quantity of electrical energy and very specific changing operating conditions of the loop, it is likely that irreducible electromagnetic interference occurs. Our objective is now to evaluate what the general characteristics of these signals in terms of frequency and conditions of occurrence are, in order to determine how this energy could be harvested.

Along the railway infrastructure there are several sources of electromagnetic signals that can reinject transient currents into the loop constituted by the traction station, the catenary wire, the train traction system and the rails. The following sources can generate signals at frequencies up to some tens of $\mathrm{kHz}$ :

- Current and voltage harmonics due to substation rectifiers

- Power electronics mounted on the vehicle

- Amplitude of the traction current

- Transient on the power circuit

- Interaction between vehicles and substations

- Signalling currents

- Distortion in the traction current

Driven by this frequency range and the loop characteristics already delivering a significant magnetic field at the very low traction energy frequency [12], we decided to concentrate this study by focusing at low frequency, between $10 \mathrm{kHz}$ and $1 \mathrm{MHz}$, and measuring the magnetic field. 


\subsection{Experimental results}

Fig. 5 represents the reference spectrum, i.e., the received spectrum obtained into the considered frequency range during quiet electromagnetic conditions, that is to say without any supplementary detectable electromagnetic activity emanating from the railway infrastructure. For this reference spectrum, there are no circulating trains and no particular detected electromagnetic activity from the wide loop participating to the received signal during the $30 \mathrm{~s}$ measurement period. Several very similar recordings were obtained during the measurement campaign; a typical result is presented in this Fig. 5. In these low activity conditions, signals accumulated over a $30 \mathrm{~s}$ period in the maximum hold mode are received at a minimum value of $-70 \mathrm{dBm}$ between $300 \mathrm{kHz}$ and $1 \mathrm{MHz}$. The received power increases up to $-40 \mathrm{dBm}$ at the starting frequency of $10 \mathrm{kHz}$. Of course, at very low frequency, $50 \mathrm{~Hz}$ in the case of the electrical network feeding the trains at the measuring location, the magnetic field induced by the loop could be high [12].

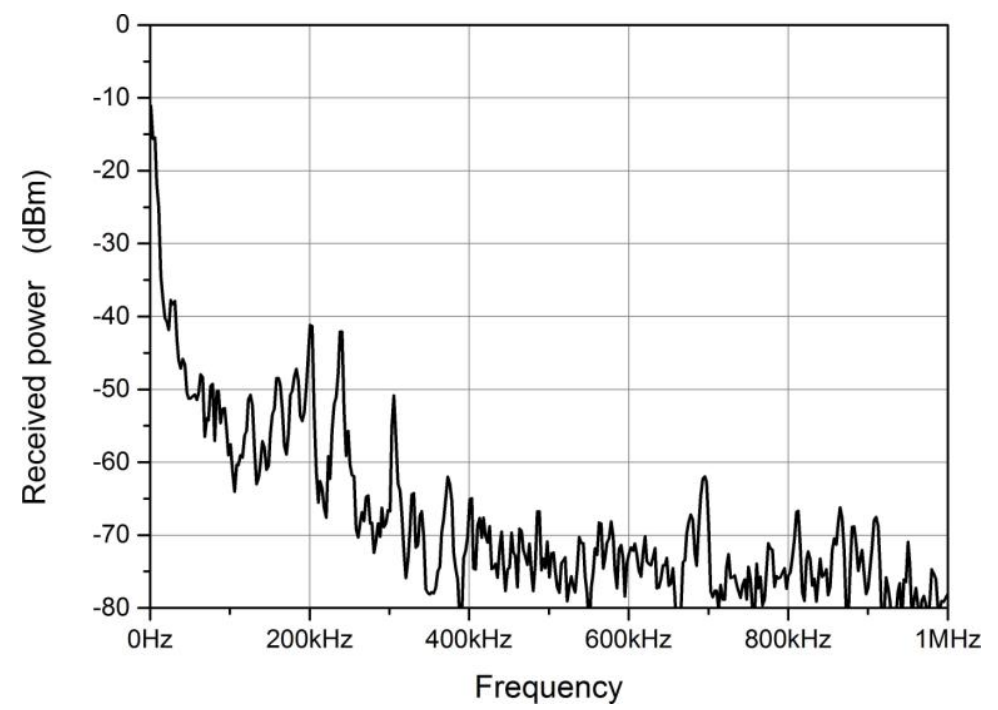

Fig. 5. Received signal in absence of electromagnetic activity.

In Fig. 6, we propose a typical result recorded while a train is circulating below the bridge. As explained previously, although the measuring location over the railway infrastructure is probably not perfect to obtain maximum magnetic field measurements, we verify that the horizontal magnetic field, perpendicular to the railway line provides the strongest received power. This was always verified in all the following magnetic field measurements of this section.

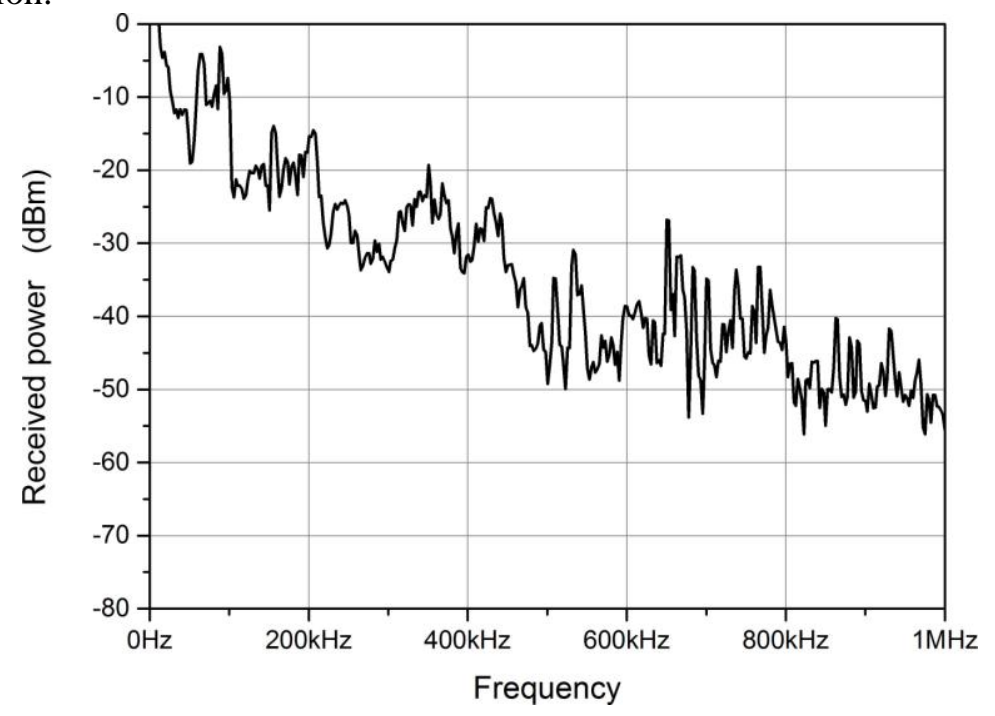

Fig. 6. Received power when a train is circulating below the bridge.

As compared to the previous low activity reference, after a 30 s maximum hold measuring period, signals globally increase by about $20 \mathrm{~dB}$ in the whole frequency band considered, and the whole spectrum is fully covered by signals 
emanating from the railway activity. Moreover, the received power decreases progressively over the two considered frequency decades showing that, as anticipated, most of the useful energy concentrates at low frequency. One complementary result that cannot be extracted from this Fig. 6 concerns how this global envelope is built. Observing on the video screen the spectrum envelope which is constructed sweep after sweep on the spectrum analyzer, we notice bursts of energy incoming erratically at discrete specific frequencies, everywhere in the studied band. After several seconds and consecutive spectrum analyzer sweeps, they globally fill the whole studied spectrum.

Fig. 7 represents another result obtained in the same operating conditions. However, in this case, two trains intersect in the bridge area during the measurement period of $30 \mathrm{~s}$. These trains come from two different manufacturers and are operated by different railway operators sharing the same infrastructure. Both trains are circulating at high speed.

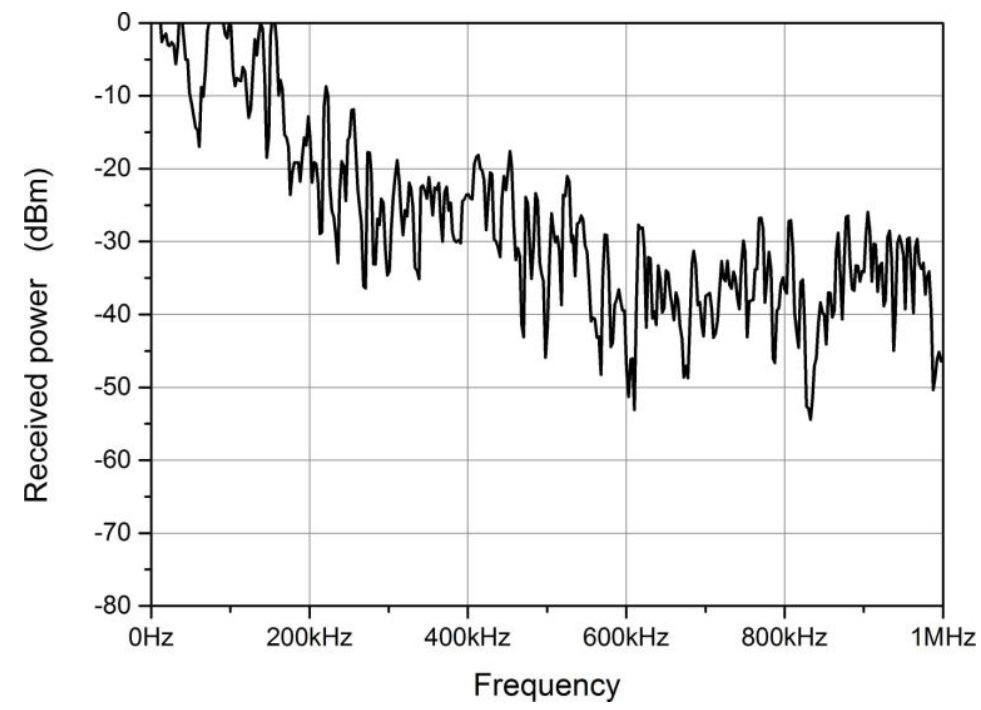

Fig. 7. Received signal, two different trains are passing below the bridge.

A maximum value of $+3.1 \mathrm{dBm}$ is recorded at $81 \mathrm{kHz}$. Although on this Fig. 7, at low frequency, the received power slightly exceeds the $0 \mathrm{dBm}$ level, we keep the same $\mathrm{Y}$ scale to propose a uniform representation of the different figures in this section using the already important $80 \mathrm{~dB}$ dynamic.

Considering these two preceding results, we obtain that energy is associated to train circulations in the vicinity of the measurement location. However, depending on the line activity, trains are not constantly circulating, and this can limit the global effectiveness of the energy harvesting process. Therefore, we have also monitored the electromagnetic signals emanating from the railway infrastructure as no trains are circulating. Fig. 8 shows such a result.

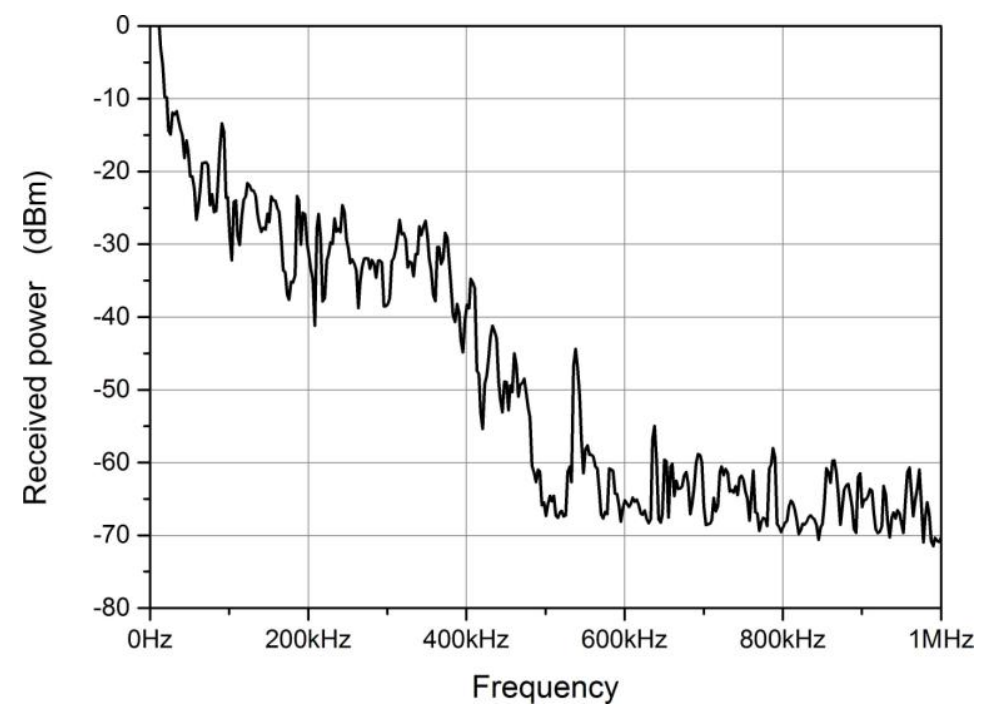

Fig. 8. Received signal, no train can be visually detected. 
In Fig. 8, as no train activity is visually discernable along the railway infrastructure, we quite often observe bursts of energy propagating along the large loop described. Considering the reference "quiet" conditions of Fig. 5 and then this Fig. 8, the received power has increased a lot, especially at frequencies below $400 \mathrm{kHz}$. An increase of $20 \mathrm{~dB}$ is measured at $200 \mathrm{kHz}$. This is explained by the signals linked to distant train traction activities located somewhere along the several tens of kilometers separating the trains and the electric substations concerned.

Finally, to extend the frequency range of observation, in Fig. 9, we present measurements performed between $10 \mathrm{kHz}$ and $30 \mathrm{MHz}$ while a train is circulating below the bridge.

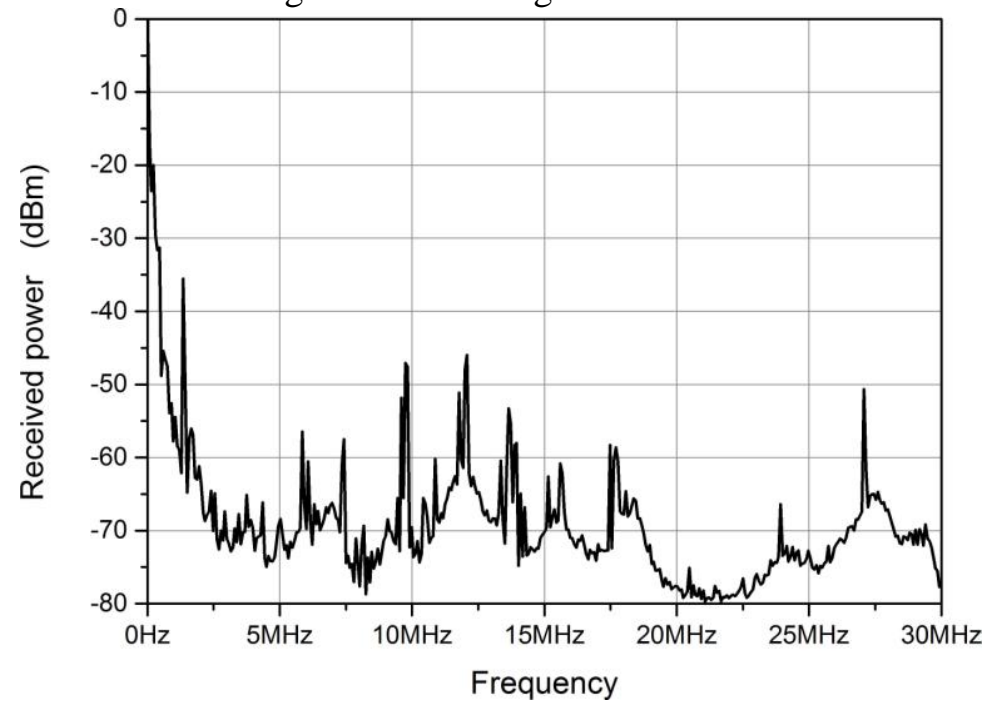

Fig. 9. Received signal, a train is passing below the bridge.

We notice that, although signals appear at higher frequency, little energy, in comparison with what we recorded below $1 \mathrm{MHz}$, is observed at higher frequencies. Therefore, most of the useful energy for our application can be extracted at low frequency, using a specifically designed rectenna. This rectenna can be developed using a shortcircuited loop whose resistive losses are the lowest possible to maximize the current induced by the incident magnetic field. A current transformer disposed on the loop raises the impedance and optimally transfers the RF energy to a diode array that is responsible for producing continuous electrical energy. This output DC energy can then be stored by various means, i.e. capacitors, batteries...

\subsection{Railway application}

Fig. 10 presents a tentative application of this electrical energy harvesting process. Low cost health infrastructure monitoring sensors, i.e. temperature, vibrations, intrusion detectors... are installed temporarily at critical railway areas. They embark a rectenna and become nomadic objects, not mechanically attached to a particular railway location.

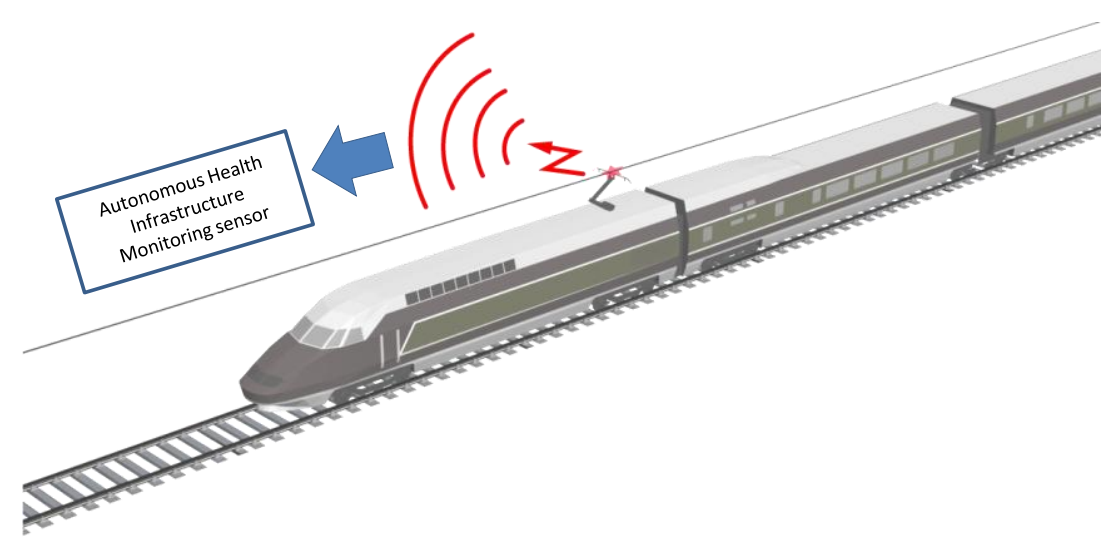

Fig. 10. Railway electromagnetic energy harvesting example of application.

Using the rectenna, the received energy is converted and used to DC feed the low consumption sensor and the associated transmitting equipment. These pieces of equipment are installed along the railway infrastructure to 
improve its resilience to internal and external aggressions. Indeed, since these rectennas, developed for the purpose of harvesting these railway line electromagnetic signals, could only operate along a railway infrastructure, it is likely that these new pieces of equipment could be very resiliently built for harsh railway environmental constraints, but also less attractive to theft than the existing ones, including solar panels.

The sensors transmit regularly the recorded infrastructure data to a distant control center. To transmit the data, they can use the newly appearing low-bandwidth cellular networks for connected objects that provide low-power as well as cost-effective connectivity for the Internet of Things [13].

\section{Catenary line and pantograph health monitoring}

\subsection{Introduction}

Train pantograph and catenary constitute very critical stakes in terms of railway maintenance [14]. Indeed, a broken catenary line has severe consequences in terms of railway exploitation, stopping trains for hours. Conventional non-destructive existing testing methods use CCTV cameras or microphones to capture images or sounds emanating from the pantograph to catenary sliding contact [15-17]. These surveillance sensors deduce, in restricted operating conditions, i.e. reduced train speed, correct or degraded performance of these train and railway infrastructure pieces of equipment.

However, the arcing phenomena also generates a wideband electromagnetic signal [18]. In the electromagnetic spectrum, this radiation is generated directly by the physical phenomenon involved in the generation of the electric arc. Such arc generators were used for radiocommunication at the beginning of radio [19], including the delivery of safety data to moving trains [20]. They permitted the very first transatlantic radio liaisons thanks to the $3-30 \mathrm{MHz}$ spectrum part of their broadband emitted signals. Indeed, the signals propagating in this high frequency (HF) band have the capability to reflect on the ionosphere layer, therefore providing long range radiocommunications via consecutive hops between the ionosphere and the earth surface [21].

Let us now consider the power supply system of a train in a different manner. The upper view of the following Fig. 11 represents a train simplified power supply system. Through a sliding contact, the catenary line feeds, via a pantograph, the train traction chain with electrical energy. Because of the imperfect sliding contact and of the huge transfer of energy, arcing phenomena occur quite often. Such an electric arc was already observed in Fig. 1. The electrical energy drives the motors, and then the return current flows through the rails, up to a distant electrical railway substation.

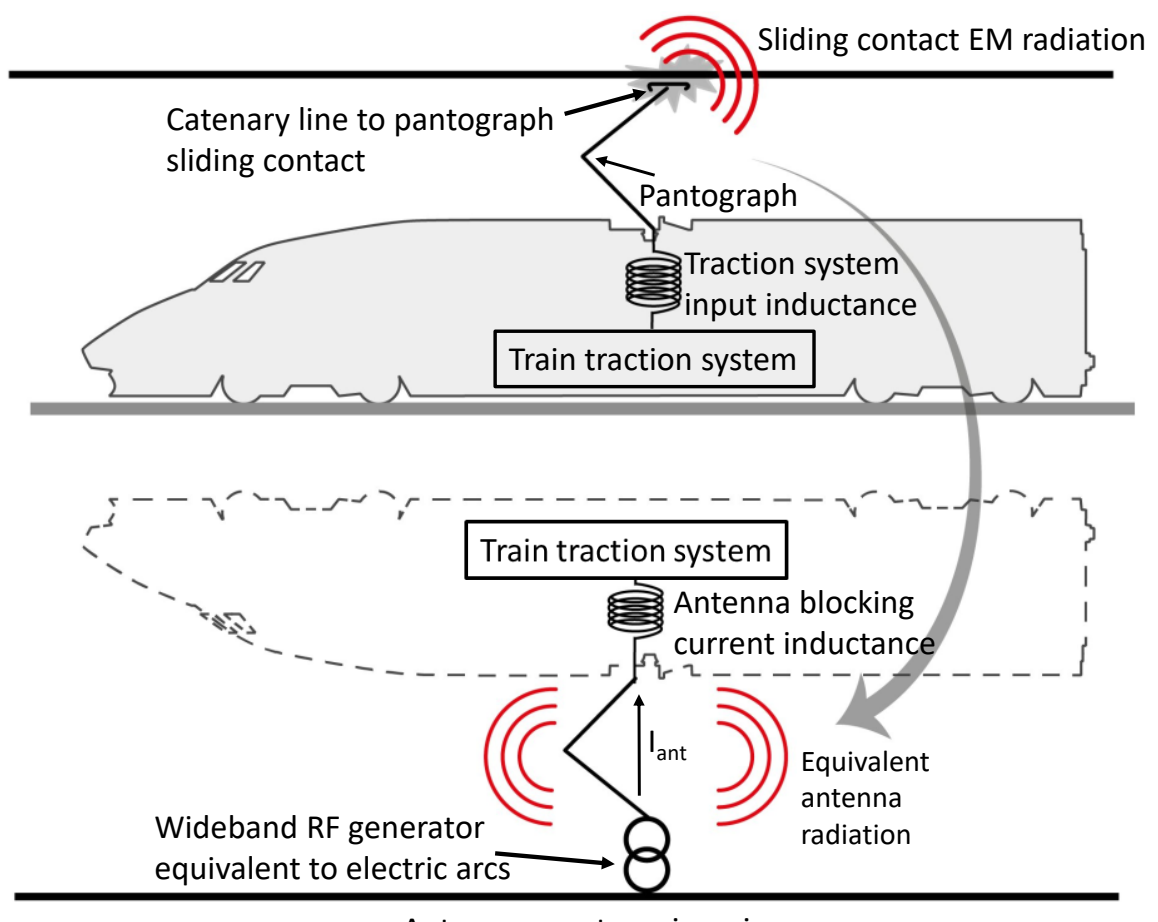

Antenna counterpoise wires

Fig. 11. Antenna system equivalent to the pantograph/catenary line. 
Now let us observe the mirror view represented in the lower part of this Fig. 11. In this view, the electrical arc is replaced by an equivalent radiofrequency generator. Depending on the junction physical characteristics, electrical arcs produce radiofrequency energy over a wide frequency range, having different electromagnetic signatures.

Therefore, we consider the pantograph to catenary line electric arc as an equivalent wideband radiofrequency generator. At its lower end, this generator is connected to a reference line constituted by the several-kilometer long catenary line extending both sides of the generator. This line can be assimilated to the reference plane of a vertical antenna installed over a conductive plane. More exactly, in our railway particular environment, this reference plane consists of counterpoise wires, or radials of vertical antennas laid at ground and often used to transmit signals of low and medium wavelength commercial broadcast transmitters [22]. At its upper extremity, this equivalent generator feeds an antenna, mostly vertically shaped, consisting in the metallic structure of the pantograph. The pantograph overall length is generally in the order of $1.5 \mathrm{~m}$. Therefore, this metallic structure can also be considered as a vertical radiator traveled by the current generator. Over the pantograph or equivalent antenna, the HF currents are blocked by the large inductance always located at the input of the train traction chain.

A $\lambda / 4$ vertical antenna laid over long counterpoise wires constitutes an effective, limited bandwidth radiating system. It radiates efficiently signals at wavelengths in the order of $1.5 \times 4=6 \mathrm{~m}$, corresponding to a central operating frequency of $50 \mathrm{MHz}$. Therefore, we can expect detecting signals radiated in this frequency band when trains are passing. As explained before, we make the assumption that these signals, mainly originating from this part of the train, would reflect some physical characteristics of the sliding contact operating conditions.

\subsection{Frequency domain analysis}

To explore this possibility, using our previously described experimental setup, we now measure the received vertical E field component between $20 \mathrm{MHz}$ and $300 \mathrm{MHz}$ in absence, and then in the presence of trains. We use the biconical antenna shown in Fig. 2. The following Fig. 12 presents the results obtained exploring this frequency band when no running trains are optically visible at our test site location, i.e. approximately 2 kilometers on each side.

A limited radiofrequency activity over this frequency band is observed. In the part of the world corresponding to these in situ measurements, the range of frequencies between $87 \mathrm{MHz}$ and $108 \mathrm{MHz}$ corresponds to the analogue Frequency Modulation (FM) broadcasting band. Therefore, we observe several FM broadcast signals of different received powers corresponding to more or less distant and powerful transmitters.

In the particular measurement campaign area, signals are also observed at $80 \mathrm{MHz}$. They are attributed to radio communications operated by the road maintenance staff.

Signals in the $30 \mathrm{MHz}$ zone are also noticeable. We will reconsider these signals in the following Fig. 13 conditions.

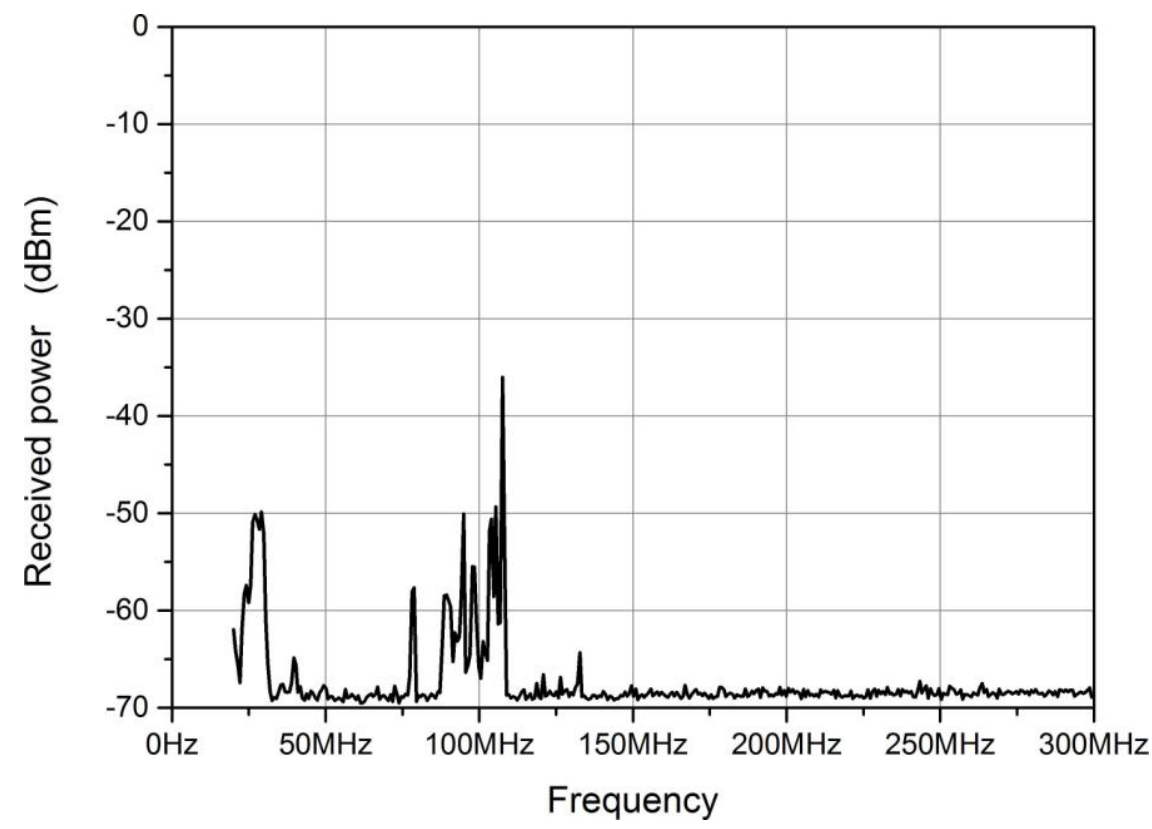

Fig. 12. Received power in the 20-300 MHz band without passing trains. 


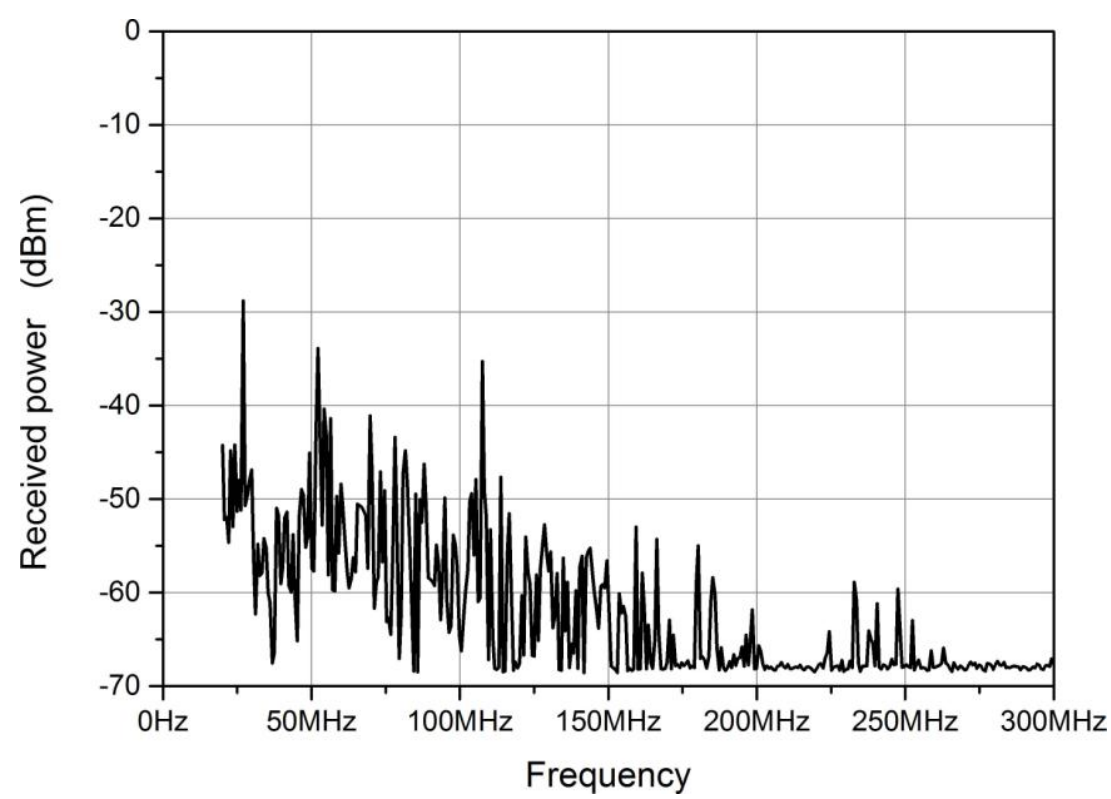

Fig. 13. Received power in the 20-300 MHz band with passing trains.

At our particular measurement location, this new Fig. 13 corresponds to typical signals recorded while trains are passing below the bridge. A much more complex frequency spectrum is recorded, superimposing train emitted signals to those already observed in Fig. 12. We verify that, as the trains move away for several hundred meters, these train signals attenuate significantly. Using our measuring conditions, they become no more detectable as the trains are out of the optical line of sight. In the observed frequency spectrum, many different spectral rays appear, occupying most of the $20 \mathrm{MHz}-300 \mathrm{MHz}$ band. Their received powers decrease progressively as the frequency increases. During several train passages, we also verify that the vertical E field component is always the strongest received one.

Let us begin the analysis of these results at the lowest recorded frequencies. For railway signalling, passive balises are installed along the track. They are used to exchange data between trains and track. Balise interrogators are mounted under the trains to communicate with the balises usually fixed on the sleepers between the rails. When a train passes, the train interrogator activates the track balise using a constantly emitted $\mathrm{HF}$ signal at $27.095 \mathrm{MHz}$ energizing the balise when situated at less than one meter [23]. Depending on the used signalization, this emitted signal can be a pure carrier or a wider bandwidth on-off keyed signal providing a reference clock signal to the balise electronics. The balise uses the $27.095 \mathrm{MHz}$ received power to activate its circuits and reflect local data to the moving train. In Fig. 13, this corresponds to a significant signal emitted by the train, observed at $27.095 \mathrm{MHz}$ and around this frequency. It was already discernible in Fig. 12 and is potentially associated to distant train balise interrogators operation.

Higher in frequency, around $50 \mathrm{MHz}$, at the previously identified frequency band, we observe in Fig. 13 specific strong signals whose received power can reach a maximum $-33 \mathrm{dBm}$ at $52 \mathrm{MHz}$. This is in line with our previous assumption concerning the particular train location origin of these signals. Therefore, it seems interesting to examine more accurately this frequency band, and a time-frequency analysis is performed to observe more in detail these results [24].

Before going to the time-frequency analysis centered in the $50 \mathrm{MHz}$ band, we observe that above this frequency band, the received signals become weaker and weaker. At $300 \mathrm{MHz}$, received signals are below the noise floor of the analyzer as configured for these measurements. Signals still exist at higher frequencies, for example at $1 \mathrm{GHz}$, where they can be of the same order of magnitude than the received signal used for train-to-ground radio communication, i.e. $-90 \mathrm{dBm}$ or less [25]. Using the monopole antenna, the measurements were continued up to $1 \mathrm{GHz}$, but no useful signals for our two proposed applications were detected in this higher frequency range.

\subsection{Time-frequency analysis}

Fig. 14 shows the time-frequency results obtained during the passage of a train. The frequency range represented covers 30 to $75 \mathrm{MHz}$. We consider 40 consecutive acquisitions, corresponding to a total observed amount of time of $100 \mathrm{~ms}$. At the speed of the train circulating in this area, close to $300 \mathrm{~km} / \mathrm{h}$, this duration corresponds to a $8.3 \mathrm{~m}$ train 
longitudinal displacement. In the frequency vs. number of acquisitions plane, the locations of the different signal components are shown. In the upper view, in ordinate, the received power is indicated.

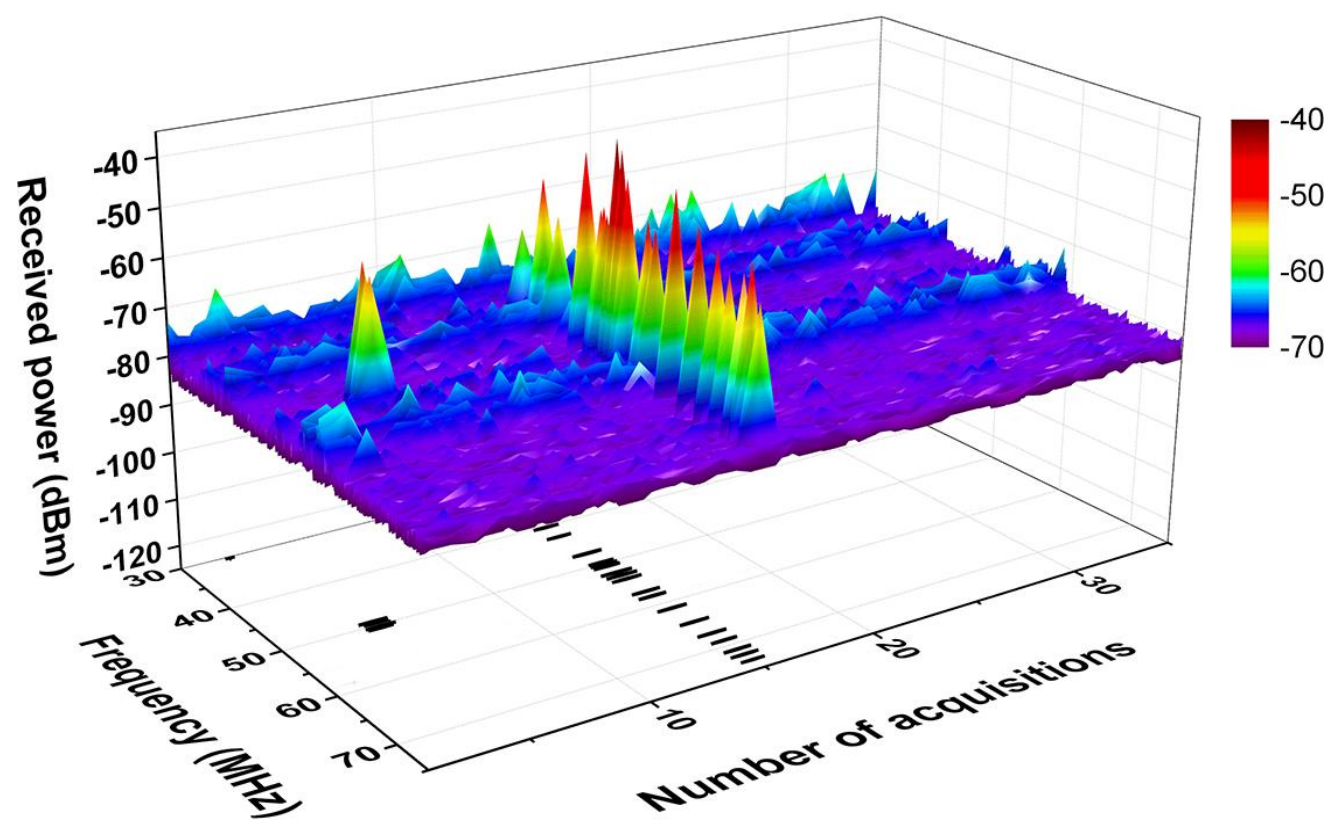

Fig. 14. Time-frequency analysis of an arc without significant bounces.

In this Fig. 14, we observe a low power precursor centered at $50 \mathrm{MHz}$. It is followed $25 \mathrm{~ms}$ later, i.e. approximately $2 \mathrm{~m}$ away, by a unique wide band much powerful signal centered at $50 \mathrm{MHz}$. The maximum received power of $-45 \mathrm{dBm}$ decreases significantly both sides of this central frequency. This signal appears very clean since it is well centered in the frequency domain. It is also time-limited without consecutive rebounds. In this particular case, we deduce from this time-frequency signature analysis that a single frank interruption of the sliding contact has occurred. Otherwise, the received signal level is sufficiently strong to enable an easy detection and analysis.

Let us now consider a second recording corresponding to a different train passage, at the same location. The corresponding results are depicted in Fig. 15.

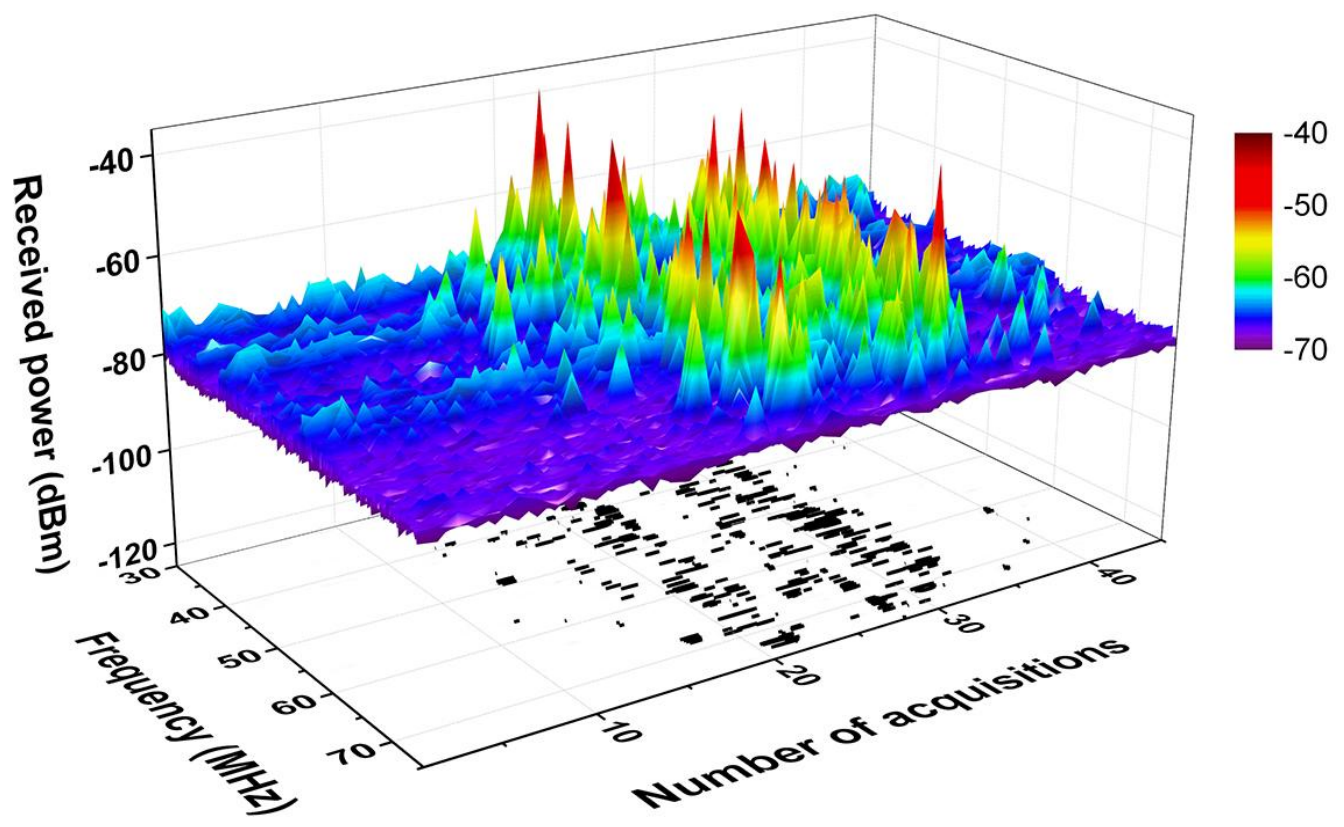

Fig. 15. Time-frequency analysis of an arc with successive bounces.

In this case, the results are much more scattered in the frequency as well as in the time domain. Signals occupy a 
larger bandwidth and numerous rebounds are observed. The corresponding received powers of the different signals are at approximately the same received power than in the previous case, i.e. $-45 \mathrm{dBm}$. Indeed the global resulting electromagnetic interference energy is much more important in this second case.

Since the location along the railway line is the same, and measurements are performed only at an interval of several minutes, we consider that the catenary line remains locally in the same mechanical and electrical shapes. Therefore, we draw the conclusion that this second train pantograph is not mechanically tuned the same way as the corresponding piece of equipment of the first train. Furthermore, this second train pantograph generates more extended electromagnetic nuisances in terms of occupied bandwidth and unnecessary radiated radiofrequency energy. Moreover, because of the numerous rebounds, such mechanical conditions could lead to premature wear of the catenary line.

\subsection{Railway application}

These results could pave the way to introducing a new nondestructive electromagnetic inspection method of the catenary line and of the train pantograph at its junction. Such a radiofrequency based system has the capability to provide a higher time resolution than existing sound or video based systems. Hence, as a perspective, a new analyzing equipment, including a vertical antenna receiving locally the strong emitted signals and an associated $50 \mathrm{MHz}$ broadband receiver providing time-frequency analysis could be developed. Used in conjunction with this hardware piece of equipment, a specific signal processing based on a classification method [25], associated to databases of VHF signatures representing known types of defaults of the pantograph and catenary line status could be developed and integrated as a new monitoring piece of equipment.

This new piece of equipment can be installed on a maintenance train circulating periodically on railway lines as a complementary non-destructive means of monitoring this particular sliding contact effectiveness. It can be also installed on the track side to monitor some critical areas before maintenance. While using this new system on the track side, or even on a train, but not easily connected to a power supply, it could be potentially DC fed by the previous energy harvesting system using the low frequency unavoidable electromagnetic interference.

\section{Conclusion}

Based on experimental measurements performed along an electrified railway line, this paper examines different assumptions which may make possible new applications of the unintentional signals emitted by the railway infrastructure. The first proposal considers energy harvesting using the received electromagnetic interference signals emitted by the railway line as a source. We obtain that, at low frequency, in the frequency range from a few $\mathrm{kHz}$ to $1 \mathrm{MHz}$, a significant amount of electromagnetic energy is emitted frequently that covers this wide frequency range. This energy input is not directly linked to local train passages. Indeed, it originates more generally from fast changing operating conditions in the transfer of electrical energy along the catenary line between the trains moving on the railway line and the remote connected electric railway substations. Since up to several MW are transferred to the trains by the catenary line and the electric substations, it is assumed that low energy, but sufficient to feed low consumption sensors, could be received and accumulated. The second proposal introduces a potential new nondestructive inspection method to monitor the health of the catenary line and of the pantograph, at their sliding contact junction. To the contrary of existing methods, we directly analyze the signal emitted from the electrical arc in the VHF band. A VHF optimum sub-band is estimated using the pantograph geometry. In this approach, the pantograph and the catenary line are considered as a vertical antenna operating over long horizontal radials. We verify a good correlation between the estimated sub-band of interest, and the one providing strong in situ signals. These experimental results are then exploited using a time-frequency analysis. Considering different trains circulating along the tested railway line, we obtain that a maximum electromagnetic energy is received in a frequency band centered at $50 \mathrm{MHz}$. We verify that these signals are effectively coming from the closely circulating trains. The time-frequency analysis provides very different results depending on the train passage evaluated. These results extend from a single frank interruption of the sliding contact to much more scattered results. The latter could correspond to pantograph to catenary line rebounds occurring over a catenary line distance of several meters. This was tentatively explained by more or less optimized pantograph mechanical and pressure adjustments regarding the different trains that generated the signals.

\section{References}

[1] Communication from the Commission to the Council and the European Parliament 2004 Critical Infrastructure Protection in the fight against terrorism available at: http://eur-lex.europa.eu/legal-content/en/TXT/?uri=CELEX\%3A52004DC0702). 
[2] Critical Infrastructure Security 2017 (US Official website of the Department of Homeland Security 2017 available at: https://www.dhs.gov/what-critical-infrastructure

[3] Khawaja AH, Huang Q and Khan ZH 2017 Monitoring of Overhead Transmission Lines: A Review from the Perspective of Contactless Technologies, Sens Imaging 18, 24

[4] The European Rail Research Advisory Council 2007 Strategic Rail Research Agenda 2020 http://www.errac.org/publications/strategicrail-research-agenda-2020

[5] Michelberger F, Wagner A, Ostermann M and Maly T 2017 Proposal of an intelligent wayside monitoring system for detection of critical ice accumulations on railway vehicles IOP Conf. Ser.: Mater. Sci. Eng. 236012047

[6] Keyrouz S and Visser H 2013 Efficient Direct-Matching Rectenna Design for RF Power Transfer Applications J. Phys.: Conf. Ser. 476 012093.

[7] Park H, Kang H, Lee Y, Park Y, Noh J, Cho G 2012 Fully roll-to-roll gravure printed rectenna on plastic foils for wireless power transmission at $13.56 \mathrm{MHz}$. Nanotechn. 23, 34344006

[8] Matiko JW, Grabham NJ, Beeby SP and Tudor MJ 2013 Review of the application of energy harvesting in buildings. Meas. Sci. Technol. 25, 1012002

[9] Wang J, Zhifei S, Hongjun X and Gangbing S 2015 Modeling on energy harvesting from a railway system using piezoelectric transducers Smart Mater Struct. 2410105017

[10] Klapas D, Hackam R and Benson FA 1976 Electric arc power collection for high-speed trains Proc. of IEEE $64121699-715$

[11] Schröder K, Ecke1 W, Kautz M, Willett S Unterwaditzer H, Bosselmann T and Rothhardt M. 2012 Smart current collector-fibre optic hit detection system for improved security on railway tracks Meas. Sci. Technol. 2411115104

[12] Bellan D, Spadacini G and Fedeli E 2013 Space-Frequency Analysis and Experimental Measurement of Magnetic Field Emissions Radiated by High-Speed Railway Systems IEEE Trans on Electromagnetic Compatibility 556 1031-42

[13] de Carvalho Silva J, Rodrigues JJ, Alberti AM 2017 LoRaWAN — A low power WAN protocol for Internet of Things: A review and opportunities Computer and Energy Science SpliTech Conf.

[14] Rusu-Anghel S and Ene A 2017 Influence of typical faults over the dynamic behavior of pantograph-catenary contact force in electric rail transport IOP Conf. Ser.: Mater. Sci. Eng. 200012056

[15] Wei W, Wu J, Gao G, Gu Z, Liu X, Zhu G and Wu G 2016 Study on Pantograph Arcing in a Laboratory Simulation System by HighSpeed Photography IEEE Trans. on Plasma Science $44102438-45$

[16] Buggy SJ, James SW, Staines S, Carroll R, Kitson P, Farrington D, Drewett L, Jaiswal J and Tatam RP 2016 Railway track component condition monitoring using optical fibre Bragg grating sensors Meas. Sci. Technol. 275055201

[17] Navik P, Ronnquist A and Stichel S 2016 A wireless railway catenary structural monitoring system: Full-scale case study Case Studies in Structural Engineering 6 22-30

[18] Karadimou E and Armstrong R 2016 Test of rolling stock electromagnetic compatibility for cross-domain interoperability IET Intelligent Transport Systems 101 10-16

[19] Pession G Montefinale 1928 Radiotelegraphic Center at Rome (San Paolo) Proc. of the Institute of Radio Engineers 16 $101404-21$

[20] Millener FH 1918 Radio Communication with Moving Trains Proc. of the Institute of Radio Engineers 6 $4185-216$

[21] Dellinger JH 1939 The role of the ionosphere in radio wave propagation Electrical Engineering $\mathbf{5 8} 11803-22$

[22] Hill DA and Wait JR 1973 Calculated pattern of a vertical antenna with a finite radial-wire ground system Radio Science $8181-5$.

[23] Wu Y, Weng J, Tang Z, Li X, Deng RH 2016 Vulnerabilities, Attacks, and Countermeasures in Balise-Based Train Control Systems IEEE Trans. on Intelligent Transportation Systems, 18, 4, pp. 814-23.

[24] Guo F, Feng X, Wang Z, You J, Wang X, Liu D and Chen Z 2017 Research on Time Domain Characteristics and Mathematical Model of Electromagnetic Radiation Noise Produced by Single Arc. IEEE Trans. on Components, Packaging and Manufacturing Tech. 10.1109/TCPMT.2017.2739157.

[25] Dudoyer S, Deniau V, Ambellouis S, Heddebaut M and Mariscotti A 2013 Classification of Transient EM Noises Depending on their Effect on the Quality of GSM-R Reception IEEE Trans. on Electromagnetic compatibility 55 867-74. 